\title{
Condensation of water vapour on moss-dominated biological soil crust, NW China
}

\author{
Xin-Ping Wang*, Yan-Xia Pan, Rui Hu, Ya-Feng Zhang and Hao Zhang \\ Shapotou Desert Research and Experiment Station, Cold and Arid Regions Environmental and Engineering \\ Research Institute, Chinese Academy of Sciences, 320, Donggang West Road, Lanzhou 730000, PR China. \\ ${ }^{*}$ Corresponding author.e-mail: xpwang@lzb.ac.cn
}

\begin{abstract}
Characteristics of water vapour condensation, including the onset, duration, and amount of water vapour condensation on moss-dominated biological soil crust (BSC) and dune sand were studied under simulated conditions with varying air temperature and relative humidity. The simulations were performed in a plant growth chamber using an electronic balance recording the weight of condensation. There was a positive linear correlation between the water vapour condensation and relative humidity while the mean temperature was negatively linearly related to amounts of water vapour condensation for both soil surfaces. The amount of water vapour condensation on BSC and dune sand can be described by the difference between air temperature and dew point with an exponential function, indicating that when the difference of air temperature and dew point exceeds a value of $35.3^{\circ} \mathrm{C}$, there will be zero water vapour condensed on BSC. In contrast, when the difference of air temperature and dew point exceeds a value of $20.4^{\circ} \mathrm{C}$, the water vapour condensation will be zero for dune sand. In general, when the air is fully saturated with water and the dew point is equal to the current air temperature, the water vapour condensed on BSC attained its maximum value of $0.398 \mathrm{~mm}$, whereas it was $0.058 \mathrm{~mm}$ for dune sand. In comparison, water vapour condensed on BSC was at a relatively high temperature and low relative humidity, while we did not detect water vapour condensation on the dune sand under the similar conditions. Physical and chemical analyses of the samples pointed to a greater porosity, high content of fine particles, and high salinity for BSC compared to the dune sand. These results highlight that soil physicochemical properties are the likely factors influencing the mechanism of water vapour condensation under specific meteorological conditions, as onset was earlier and the duration was longer for water vapour condensation on BSC in comparison with that of dune sand. This contributed to the greater amount of vapour absorbed on BSC compared to the dune sand under an identical meteorological condition. The feedback of water vapour condensation on BSC formation and its contribution to sustain the revegetation desert ecosystems was discussed.
\end{abstract}

\section{Introduction}

Water vapour exchange at the earth's surface has received increasing attention in desert ecology. Though the condensation of water vapour has a far-smaller quantitative output relative to rainfall, it is a very common natural phenomenon and has ecological significance (Stone 1963). Dew, one of the major condensed water vapour, occurs when humid air condenses onto a substrate and transforms into liquid water (Beysens 1995; Veste et al. 2008), and originates either from air (dewfall) or from soil (Wells 1815; Aitken 1885; Monteith 1957; Garratt and Segal 1988). Considering the

Keywords. Condensation; water vapour; desert ecosystem; moss; biological soil crust. 
dry soil moisture conditions in desert area, dew amount from the soil is comparatively small. Thus, in deserts, dewfall from air accounts for more than 90\% of the total dew amounts (Pan et al. 2010). Its active layer is limited to the first $3 \mathrm{~cm}$ depth of the upper soil in the arid Shapotou, NW China (Pan et al. 2010). Dew research, however, requires a multidisciplinary perspective because of the many complex ways in which dew can be an ecosystem 'engine' (Veste et al. 2008). There are a number of publications on the formation of dew on varied soil surfaces in arid and semi-arid desert regions ( $\mathrm{Li}$ et al. 2002; Heusinkveld et al. 2006). For instance, it has been shown that dew deposition on biological soil crust (BSC) differs according to the level of its development, weather conditions and habitats and microhabitats of the shrub vegetation, whether BSC established or not (Kidron 2000, 2010; Pan et al. 2010).

Beysens (1995) reviewed the formation process of dew and indicated that dew can be controlled by two key parameters: temperature and wetting properties of the substrate. Other studies show meteorological factors and substrate characteristics are most important in influencing the formation of dew. Low air and soil surface temperature (Monteith 1957; Angus 1958; Duvdevani 1964; Li 2002), high air relative humidity (Zangvil and Druian 1980; Ye et al. 2007), and moderate wind speed (Monteith 1957; Beysens 1995) are the most appropriate weather conditions for the formation of dew. Moreover, the type of condensing surface ( $\mathrm{Li}$ 2002), soil moisture content (Zheng 1963), development of BSC and its components (Kidron et al. 2002; Pan et al. 2010) and other factors such as relative elevation (Subramanian and Kesava-Rao 1983), and soil salinity (Heusinkveld et al. 2006) also affect the amounts of dew formed. Dew has been demonstrated to be an additional water supply in the surface soil, the effect of dew on different BSC was evaluated long ago (Kidron et al. 2002). Kidron et al. (2002) showed that while cyanobacterial crusts condensed small amounts, moss-dominated crusts were much more efficient in condensing dew, and ascribed it to the structure of the mosses that protrude above the surface. However, the general studies on the effects of soil structure of the uppermost surface in terms of the pore size distribution to water vapour condensation have not occurred.

According to the review of Stone (1963), several formulae have been derived in an effort to estimate the occurrence, duration and amount of dew. These equations combine standard meteorological data with characteristics of condensing surfaces. Clus et al. (2009) used computational fluid dynamics to characterize and compare designs for dew condensers in specific environmental settings.
A recent field study at Shapotou, NW China showed that the relative humidity and temperature were more strongly related to dew amounts than wind speed (Pan et al. 2010). However, no systematic research has been conducted to analyze and explore the threshold value of air temperature and/or dew point influence on the mechanisms of dew formation. When does dew accumulation begin in a desert ecosystem, and how long can dew persist before evaporating?

In NW China, revegetation is one of the successful methods to stabilize sand dunes. Dune stabilization through the revegetation of xerophytic shrubs produces a wide range of ecological and hydrological effects, the generation of BSC occurs on the original sand surface through dust and fine materials deposition, and thus results in a significant regulation of the hydrological process, such as, the water balance changes (Wang et al. 2004), infiltration processes and soil moisture variation (Wang et al. 2007).

In this paper, our goal is to improve understanding of condensation of water vapour on two typical condensate surface types within a revegetated desert ecosystem at the Shapotou Desert Research Station: those with moss-dominated BSC and dune sand. Using these two surfaces, we quantified the dependence of the rate of condensed water vapour accumulation and its duration on different air temperature and relative humidity conditions. Also, we examined how condensation of water vapour was influenced by the type of soil surface, as well as the potential maximum amount of condensed water vapour on these two types of soil surfaces. Finally, we constructed a conceptual model showing the relationship between the water vapour condensation and environmental conditions, on the basis of differences between air temperature and dew point.

\section{Materials and methods}

\subsection{Experimental design and data collection}

A condensation of water vapour measurement program was carried out with BSC and dune sand in July and August, 2010, in a Thermoline's TPG5000-TH plant growth chamber (Thermoline Scientific, Australia) with a growing area size of 5000 litres, operated at Shapotou Desert Experimental Research Station, Chinese Academy of Sciences. Air temperatures of $5^{\circ}, 10^{\circ}, 15^{\circ}, 20^{\circ}, 25^{\circ}$, and $30^{\circ} \mathrm{C}$, and relative humidity $(\mathrm{RH})$ of $30,40,50,60$, 70,80 , and $90 \%$ was applied; there were 42 treatments in terms of the pairs of temperature and $\mathrm{RH}$ combinations (6 temperature $\times 7 \mathrm{RH}=42$ ).

Quartz glass containers (40 cm in length, $30 \mathrm{~cm}$ in width, and $7.5 \mathrm{~cm}$ in height) were pushed into 
the soil to collect undisturbed soil columns of BSC and dune sand manually. After the frame of the container pushed into soil surface, a pit was dug out to the bottom of the container, then a platen of quartz glass was inserted into the soil just below the frame of the container horizontally and sealed promptly by glass cement. The samples were airdried and then taken back to the laboratory and placed on two electrical balances (sensitivity $\leq \pm$ $0.1 \mathrm{~g}$; pan size: $40 \times 30 \mathrm{~cm}$; Model: CPA34001S, Florenz Sartorius Co., Germany) inside the chamber. As the sensitivity of the balance was $0.1 \mathrm{~g}$ and the soil sample surface area was $1200 \mathrm{~cm}^{2}$, we were able to resolve resolution of $0.8 \times 10^{-4} \mathrm{~mm}$ (in equivalent depth of water covering the sample surface). These balances mounted with soil samples were placed in the plant growth chamber for consecutive mass weighing, thus acting as automated microlysimeters (e.g., Ninari and Berliner 2002; Heusinkveld et al. 2006). The samples of BSC and dune sand on electrical balance were weighed simultaneously at intervals throughout the whole experimental period until no further change in weight was detected. Data were measured and collected using a CR1000 data logger (Campbell Corporation, CA, USA) with a frequency of $2 \mathrm{~s}$, automatically averaged over $10 \mathrm{~min}$. All measurements were replicated three times on the same soil samples. The onset time of dew formation and water absorption was determined by calculating the difference time between the beginning of the weight increment of the soil sample and the start of simulation, and the end time of dew formation and water absorption was determined by calculating the time when no weight increment was detected for consecutive $10 \mathrm{~min}$ of the soil sample. Temperatures of dune sand and BSC surface were measured by a system of thermocouples (Pentronic 80-40000, Gunnebobruk, Sweden) with a range from 0 to $200^{\circ} \mathrm{C}$ and an accuracy of $\pm 0.1^{\circ} \mathrm{C}$ with connections (Pentronic 11-00106, K 106, Gunnebobruk, Sweden). Temperature readings were taken by using a portable recorder of TC-1100 Digital Thermocouple Thermometer (Line Seiki Co. Ltd., Tokyo, Japan) outside the growth chamber. The thermocouples were calibrated in laboratory to correct for differences in each sensor's temperature range.

\subsection{Soil (physical and chemical) properties analysis}

After the condensation of water vapour measurements, soil samples were analyzed for physical and chemical properties. Soil bulk density was estimated by in-situ volume of removed soil (McDonald 1994) for dune sand or by wax-coated clod (Singer 1986) for BSC, soil particle size distribution was analyzed using MS-S lighter scattering apparatus (Malvern Instruments Ltd., UK), soil porosity was measured by high-resolution microCT using a SkyScan 1172 scanner with a resolution of $5 \mu \mathrm{m}$ (SkyScan Co., Belgium), soil pH was measured in water (soil: water ratio $=1: 5$ ) with a calibrated Thermo pH Meter (VWR sympHony pH Meters SP70P Handheld Meter, USA), and soil organic matter was analyzed by potassium dichromate volumetric method using $\mathrm{K}_{2} \mathrm{Cr}_{2} \mathrm{O}_{7}$. Electrical conductivity was measured using Corning Model 311 Portable Conductivity Meter (Cole-Parmer Instrument Co., USA).

\subsection{Data analysis}

The amount of condensation of water vapour $(h$, $\mathrm{mm}$ ) was calculated as:

$$
h=\frac{10 \cdot m}{\rho \cdot a \cdot b},
$$

where $m$ is the mass $(\mathrm{g})$ of amount of condensation of water vapour measured by the balance; $\rho$ is water density $\left(\mathrm{g} \mathrm{cm}^{-3}\right) ; a$ and $b$ are length $(\mathrm{cm})$ and width $(\mathrm{cm})$ of the sample; 10 is the factor to convert the water depth from centimeter to millimeter. For data analysis at each temperature and $\mathrm{RH}$ combination, the difference of dew and water vapour condensation onset, duration, and amount between temperature and $\mathrm{RH}$ was quantified using analysis of variance (one-way ANOVA). Bonferroni corrected test for homogeneity of variance was also applied post-hoc to distinguish between mean temperature and $\mathrm{RH}$ using window-based SPSS 12th edition software (Chicago, USA). All levels of statistical significance are given at $p<0.05$.

\section{Results and discussions}

\subsection{The formation characteristics of dew and water vapour condensation}

For dew to deposit on a surface, the prerequisite is that the temperature of the surface has to be equal to, or less than the dew point temperature of the airmass that it is in contact with. The observation for present simulation revealed that usually, the soil surface temperature did not drop below the estimated dew point temperature except under an $\mathrm{RH}$ of $90 \%$ through all simulated air temperatures (table 1), but a noticeable increment in the weight and/or mass (e.g., surface soil moisture) of the soil samples was observed manifesting that dew and vapour condensation processes were beginning (figure 1), which was consistent with the measurement carried out in the Northern Negev, Israel (Agam and Berliner 2004). This indicated that the increase of surface soil moisture was not only due 
Table 1. Dew point $\left(D P,{ }^{\circ} C\right)$ and surface temperature of biological soil crust $\left(T_{B S C},{ }^{\circ} C\right)$ and dune sand $\left(T_{D S},{ }^{\circ} C\right)$ under different $R H$ and air temperatures.

\begin{tabular}{|c|c|c|c|c|c|c|c|c|c|c|c|c|c|c|c|c|c|c|}
\hline \multirow{2}{*}{$\begin{array}{l}\mathrm{RH} \\
(\%)\end{array}$} & \multicolumn{3}{|c|}{$5^{\circ} \mathrm{C}$} & \multicolumn{3}{|c|}{$10^{\circ} \mathrm{C}$} & \multicolumn{3}{|c|}{$15^{\circ} \mathrm{C}$} & \multicolumn{3}{|c|}{$20^{\circ} \mathrm{C}$} & \multicolumn{3}{|c|}{$25^{\circ} \mathrm{C}$} & \multicolumn{3}{|c|}{$30^{\circ} \mathrm{C}$} \\
\hline & $\mathrm{DP}$ & $\mathrm{T}_{\mathrm{BSC}}$ & $\overline{\mathrm{T}_{\mathrm{DS}}}$ & $\overline{D P}$ & $\mathrm{~T}_{\mathrm{BSC}}$ & $\overline{\mathrm{T}_{\mathrm{DS}}}$ & $\overline{\mathrm{DP}}$ & $\mathrm{T}_{\mathrm{BSC}}$ & $\overline{\mathrm{T}_{\mathrm{DS}}}$ & $\overline{\mathrm{DP}}$ & $\mathrm{T}_{\mathrm{BSC}}$ & $\overline{\mathrm{T}_{\mathrm{DS}}}$ & $\overline{\mathrm{DP}}$ & $\mathrm{T}_{\mathrm{BSC}}$ & $\overline{\mathrm{T}_{\mathrm{DS}}}$ & $\overline{\mathrm{DP}}$ & $\mathrm{T}_{\mathrm{BSC}}$ & $\mathrm{T}_{\mathrm{DS}}$ \\
\hline 0 & -11.1 & 2.1 & 2.2 & -6.8 & 6.9 & 7.0 & -2.4 & 12.0 & 12.1 & 1.9 & 16.9 & 17.1 & 6.2 & 22.0 & 22.1 & 10.5 & 27.2 & 27.3 \\
\hline 40 & -7.5 & 2.1 & 2.2 & -3.0 & 6.9 & 7.0 & 1.5 & 12.0 & 12.1 & 6.0 & 16.9 & 17.1 & 10.5 & 22.0 & 22.1 & 14.9 & 27.2 & 27.3 \\
\hline 50 & -4.5 & 2.0 & 2.1 & 0.1 & 6.8 & 7.0 & 4.7 & 11.9 & 12.1 & 9.3 & 16.8 & 17.1 & 13.9 & 21.9 & 22.1 & 18.4 & 27.1 & 27.2 \\
\hline 50 & -2.1 & 2.0 & 2.1 & 2.6 & 6.8 & 7.0 & 7.3 & 11.9 & 12.0 & 12.0 & 16.8 & 17.0 & 16.7 & 21.9 & 22.0 & 21.4 & 27.1 & 27.2 \\
\hline 10 & 0.0 & 2.0 & 2.1 & 4.8 & 6.8 & 6.9 & 9.6 & 11.8 & 12.0 & 14.4 & 16.7 & 16.9 & 19.1 & 21.8 & 22.0 & 23.9 & 27.0 & 27.1 \\
\hline & 1.8 & 1.9 & 2.0 & 6.7 & 6.8 & 6.9 & 11.6 & 11.7 & 11.9 & 16.4 & 16.7 & 16.8 & 21.3 & 21.7 & 22.0 & 26.2 & 27.0 & 27.1 \\
\hline 0 & 3.5 & 1.9 & 2.0 & 8.4 & 6.7 & 6.8 & 13.4 & 11.7 & 11.9 & 18.3 & 16.6 & 16.8 & 23.2 & 21.7 & 21.9 & 28.2 & 26.9 & 27.0 \\
\hline
\end{tabular}

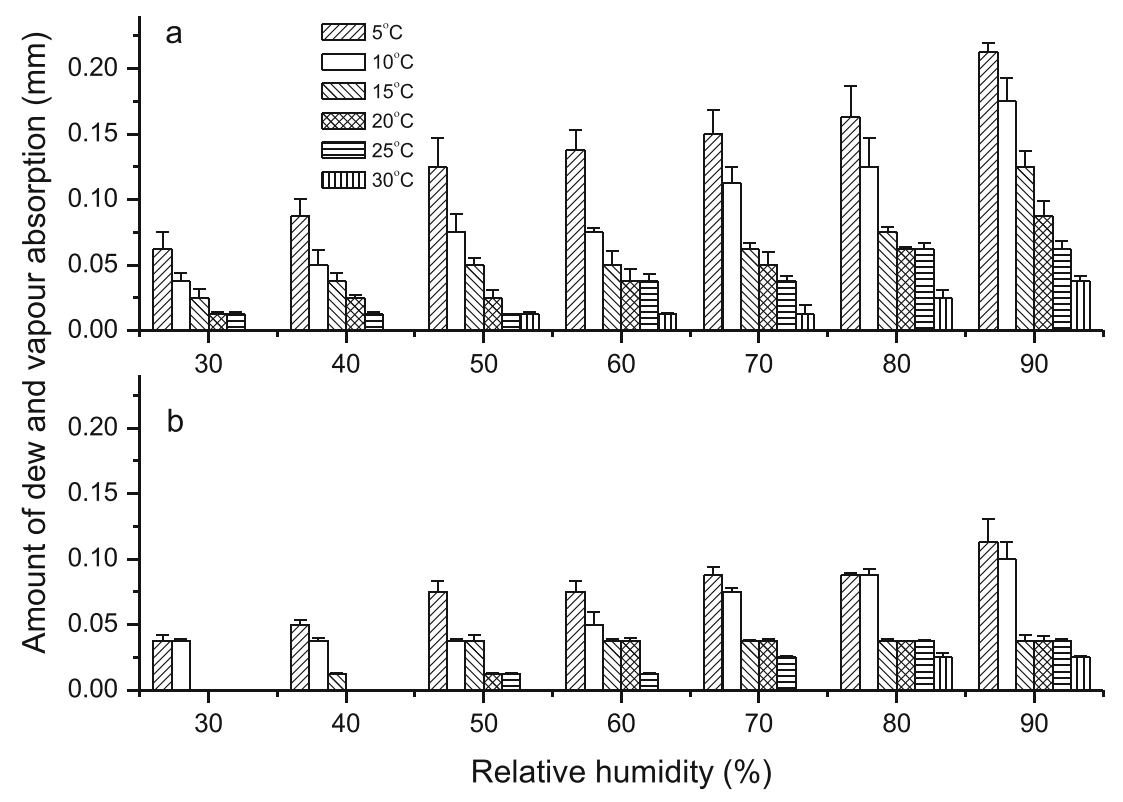

Figure 1. The amount of dew and vapour absorption on BSC (a) and bare dune sand (b) versus $\mathrm{RH}$ under different air temperatures. Vertical bars present the standard error.

to the formation of dew. Due to extremely low surface moisture content of both BSC and sand (air dried), according to the analysis of Philip and de Vries (1957), the dominant mechanism is adsorption, indicating that moisture was absorbed by the soil during the simulation experiment. The air dried soil sample of BSC and dune sand induces the water vapour content at the soil pores is less than that of simulated air conditions (varied air temperature and $\mathrm{RH}$ ), water adsorption process arises easily and plays an important role in the present study. So the water vapour condensation in this paper included both dew formation and water vapour absorption. There was no dew and water vapour condensation on BSCs when the air temperature exceeded $30^{\circ} \mathrm{C}$ and $\mathrm{RH}$ was below $40 \%$. For dune sand, there was no dew and water vapour condensation when temperatures were above $15^{\circ} \mathrm{C}$ and $\mathrm{RH}$ was below $40 \%$, temperatures above $20^{\circ} \mathrm{C}$ and $\mathrm{RH}$ below $50 \%$, temperatures above $25^{\circ} \mathrm{C}$ and $\mathrm{RH}$ below $50 \%$, or temperatures above $30^{\circ} \mathrm{C}$ and $\mathrm{RH}$ below $70 \%$ (figure 1).

\subsection{Onset time and duration of dew and water vapour condensation}

The length of time it takes for dew and water vapour condensation to begin, to form and to remain on the condensing surface may be of more importance than the total amount of dew deposited (Kidron et al. 2011). Note that in the present study, we defined onset time of dew and water vapour condensation as the time from the point that samples were put into the experimental chamber until dew and water vapour condensation was observed. The onset time of formation of dew and water vapour condensation was $0.45,0.4,0.4,0.28,0.2,0.32$, and $0.25 \mathrm{~h}$ on BSC among all gradients of $\mathrm{RH}$ when the air temperature was $5^{\circ} \mathrm{C}$. It was $0.6,0.5,0.4,0.47$, $0.42,0.47$, and $0.32 \mathrm{~h}$ on sand surface. By comparing the difference between air temperature and dew point (table 1), it is relatively smaller under a lower air temperature such as at $5^{\circ} \mathrm{C}$ than at other higher temperatures among all gradients of $\mathrm{RH}$. Under higher temperatures, $\mathrm{RH}$ will merge into a 


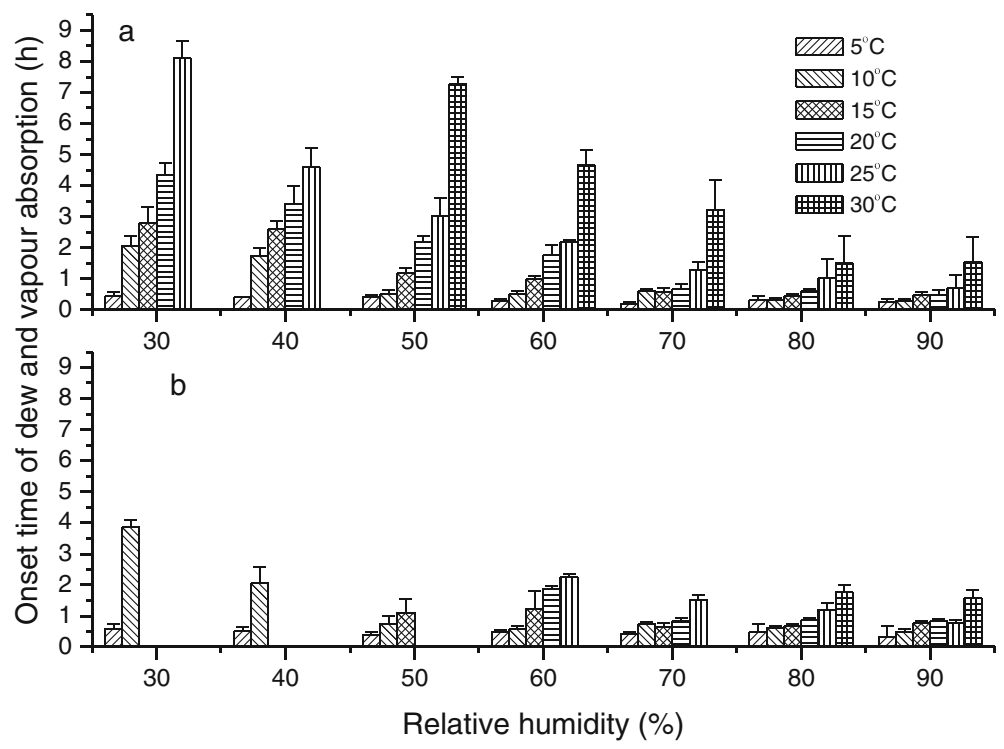

Figure 2. The onset time of dew and vapour absorption on BSC (a) and bare dune sand (b) versus $\mathrm{RH}$ under different air temperatures. Vertical bars present the standard error.

Table 2. Duration (h) of dew and vapour absorption on BSC and dune sand under different RH and air temperatures.

\begin{tabular}{|c|c|c|c|c|c|c|c|c|c|c|c|c|}
\hline \multirow{2}{*}{$\begin{array}{l}\text { RH } \\
(\%)\end{array}$} & \multicolumn{6}{|c|}{ Biological soil crust } & \multicolumn{6}{|c|}{ Dune sand } \\
\hline & $\overline{5^{\circ} \mathrm{C}}$ & $10^{\circ} \mathrm{C}$ & $15^{\circ} \mathrm{C}$ & $20^{\circ} \mathrm{C}$ & $25^{\circ} \mathrm{C}$ & $30^{\circ} \mathrm{C}$ & $\overline{5^{\circ} \mathrm{C}}$ & $10^{\circ} \mathrm{C}$ & $15^{\circ} \mathrm{C}$ & $20^{\circ} \mathrm{C}$ & $25^{\circ} \mathrm{C}$ & $30^{\circ} \mathrm{C}$ \\
\hline 30 & 6.2 & 5.5 & 5.6 & 4.5 & 2.0 & 0.0 & 3.3 & 2.0 & 0.0 & 0.0 & 0.0 & 0.0 \\
\hline 40 & 6.0 & 5.8 & 5.0 & 4.5 & 3.0 & 0.0 & 3.5 & 2.8 & 0.0 & 0.0 & 0.0 & 0.0 \\
\hline 50 & 6.5 & 6.0 & 5.6 & 5.0 & 3.3 & 2.0 & 4.0 & 3.6 & 2.6 & 0.0 & 0.0 & 0.0 \\
\hline 60 & 7.0 & 6.4 & 6.0 & 5.6 & 4.0 & 3.5 & 5.0 & 4.4 & 3.0 & 2.6 & 1.5 & 0.0 \\
\hline 70 & 7.8 & 7.0 & 6.0 & 6.3 & 4.5 & 4.0 & 5.8 & 4.3 & 3.5 & 2.3 & 1.5 & 0.0 \\
\hline 80 & 8.5 & 8.0 & 7.0 & 7.0 & 5.0 & 3.7 & 5.5 & 4.0 & 3.0 & 3.0 & 3.0 & 1.0 \\
\hline 90 & 9.0 & 8.3 & 7.0 & 7.5 & 6.4 & 4.0 & 6.0 & 5.0 & 4.0 & 3.5 & 3.0 & 1.0 \\
\hline
\end{tabular}

relatively significant influencing factor in attributing to the vapour absorption on both surfaces, inducing a big difference in onset times of dew formation and vapour absorption. For a given treatment of air temperature and $\mathrm{RH}$, the occurrence of dew and water vapour condensation was on average $0.21 \mathrm{~h}$ earlier for BSC compared to dune sand (figure 2).

The measurements also revealed that the average duration of dew and water vapour condensation could last for $5.65 \mathrm{~h}$ on BSC, with air temperature varying from $5^{\circ}$ to $30^{\circ} \mathrm{C}$, and $\mathrm{RH}$ from 30 to $90 \%$, while it lasted on dune sand for $3.37 \mathrm{~h}$. The maximum dew and water vapour condensation duration was $9 \mathrm{~h}$ and $6 \mathrm{~h}$ on BSC and dune sand, respectively, with air temperature $5^{\circ} \mathrm{C}$ and RH 90\% (table 2). Pedro and Gillespie (1982) using a computed surface energy balance and latent heat flux to estimate the dew duration, found an average maximum dew formation equal to 11.6 and $13.0 \mathrm{~h}$ for exposed corn and soybean leaves, respectively, and it was average 12.1, 13.0, and $13.7 \mathrm{~h}$ for shaded apple, corn, and soybean leaves, respectively. This shows that the type of condensing surface is an important factor in duration of dew and water vapour condensation. In the present study with two typical soil surfaces, the shorter time to dew and water vapour condensation occurrence, and the longer duration of dew and water vapour condensation on BSC relative to dune sand. This is because the physicochemical properties of the underlying soil can determine the soil water retention condition to a large extent, and hence play a significant role in dew and water vapour condensation and soil water content retaining, which means that, within the uppermost soil layer, more moisture in BSC is available longer to the cryptogams and associated organisms such as fungi, soil microfauna and shallow-rooting plants. The data also suggest that even in dry seasons with $\mathrm{RH}$ of $30 \%$, dew and water vapour condensation input may in fact persist throughout the period with the temperature below $25^{\circ} \mathrm{C}$ on $\mathrm{BSC}$ in comparison with dune sand (figure 1). 


\subsection{The influence of the difference between air temperature and dew point}

The dew point is a measure of the amount of moisture in the air and thus indicates the amount of moisture available for condensation. The difference between air temperature and dew point is a measure of the amount of radiative cooling required before dew can form. In this study, the dew point was calculated using the method of Jensen et al. (1990), and the difference between actual air temperature and dew point was then grouped by series of $\mathrm{RH}$ treatment. Hence, seven groups of averaged difference between air temperature and dew point were available for analysis (figure 3 ). These data showing the amount of dew and water vapour condensed on BSC and dune sand can be described using an exponential function. The resulting fitted formulas for calculating dew and water vapour condensed on BSC and dune sand are also shown in figure 3. It can be seen that when the difference between air temperature and dew point exceeds $35.3^{\circ} \mathrm{C}$ and $20.4^{\circ} \mathrm{C}$, there will be zero dew and water vapour condensed on the surface of BSC and bare dune sand, respectively. In the case when the air is fully saturated with water vapour and the dew point is equal to the actual air temperature, the dew and water vapour condensed on BSC will reach its maximum value of $0.398 \mathrm{~mm}$, whereas it is $0.058 \mathrm{~mm}$ only on dune sand.

Beysens (1995) studied the control of dew formation and pointed out that an 'ideal' condenser should be 'grass-like', i.e., a light sheet thermally isolated from massive parts and from the ground and in an open area to radiate the energy. The BSC in the present study were dominated by abundant mosses (Li et al. 2002). They are 'grass-like' on the soil top surface and could be an ideal condenser as compared to the bare dune sand surface (Kidron et al. 2002).

Because precipitation in the Tengger Desert, NW China is restricted to infrequent rains during the short rainfall season from June to September, atmospheric moisture in the form of dew can be a major and regular supplier of water for cryptogams and other surface-dwelling organisms. Such apparently insignificant but regular moisture contribution can play an important role in desert ecosystems. Thus one of the ecologically significant roles of BSC in arid desert regions is their influence on the amount and duration of dew and water vapour condensation under appropriate meteorological conditions. This directly affects the water status of the surface soils and leads to the availability of water to cryptogams, indigenous plants, and ephemeral plants. Dew and water vapour condensation may also assist in the adhesion of dust and fine materials to soil surface.

\subsection{Pore size distribution and porosity}

Pore size distribution of dune sand is strongly unimodal with a very short range of pore sizes (ranges from 10.5 to $115.5 \mu \mathrm{m}$ ) and comprises of a total porosity of $38.9 \%$, whereas the corresponding value for BSC is $57.9 \%$ with a wider range of pore sizes (ranges from 15 to $385 \mu \mathrm{m}$ ). The maximum porosity for dune sand is $7.9 \%$ corresponding to a pore diameter of $38.5 \mu \mathrm{m}$, while it is $5.6 \%$ in porosity and $45.5 \mu \mathrm{m}$ in pore diameter for BSC. Comparison shows that a progressive decrease of smaller pores and increase of larger pores is also evident in BSC

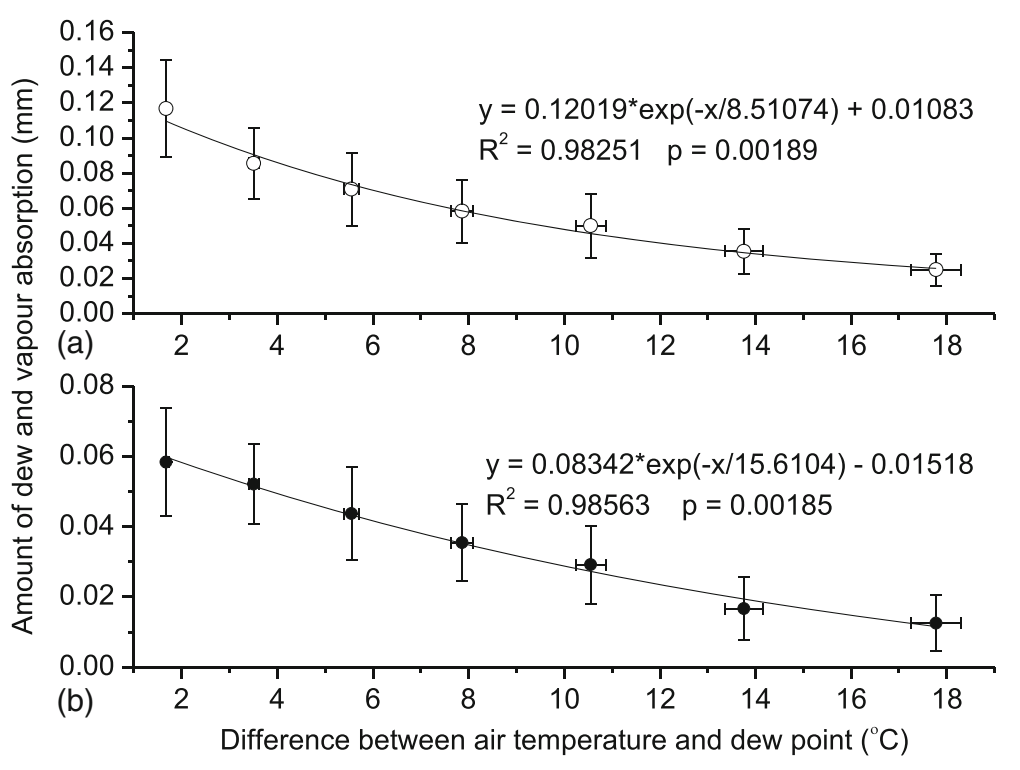

Figure 3. The amount of dew and vapour absorption on BSC (a) and bare dune sand (b) versus difference between air temperatures and dew point. Horizontal and vertical bars present the standard error. 


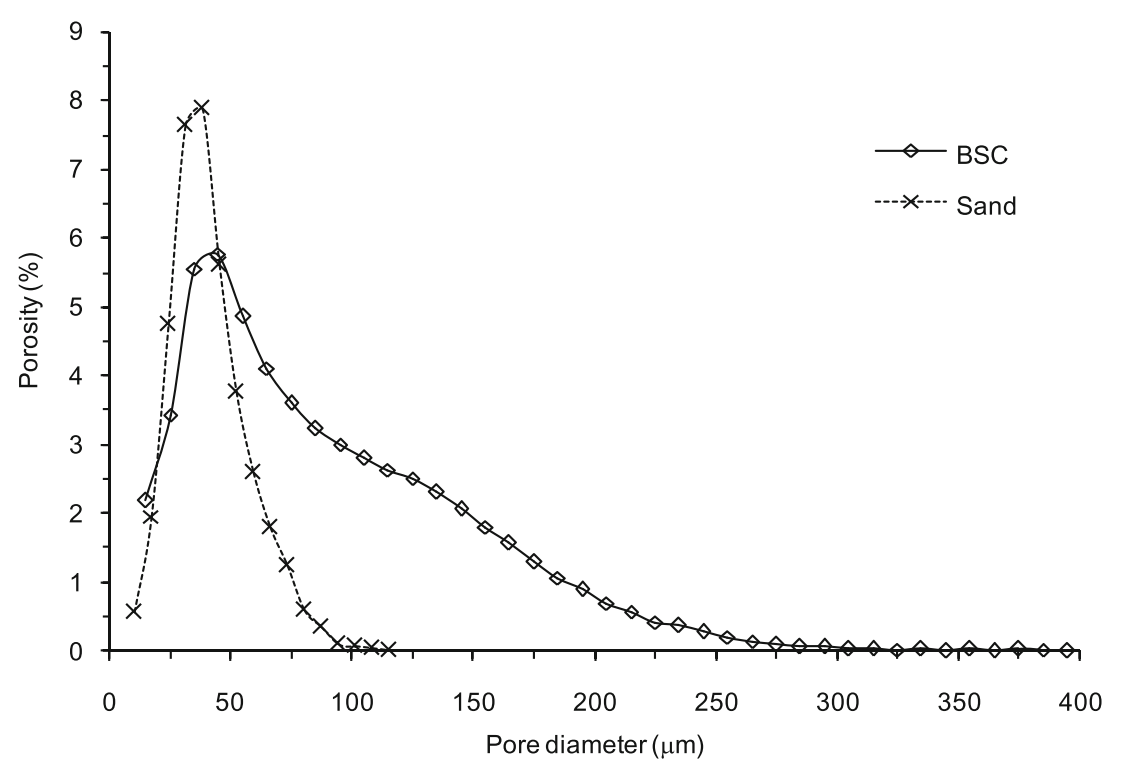

Figure 4. The porosity distribution of BSC and dune sand versus the pore diameter.

(figure 4). The significant difference in porosity of BSC and dune sand is, therefore, an increment in both of volume of pores and porosity in BSC.

\subsection{Influence of soil properties on water vapour condensation}

The total dew and condensed water vapour variation in the samples over the 42 treatments (6 air temperatures $\times 7$ relative humidity) ranged up to $0.11 \mathrm{~mm}$ on bare dune sand and up to $0.21 \mathrm{~mm}$ on BSC (figure 3). The recording microlysimeters highlighted that the bare dune sand consistently averaged $48 \%$ less dew and water vapour condensation than on the BSC, which indicates that the actual amount of dew and water vapour condensation in a specific microhabitat is strongly dependent on ground surface properties. This difference is attributed to the higher silt and clay content, organic matter, porosity and salinity in BSC relative to dune sand (table 3 ). Fine particles increase water adsorption under extremely low soil moisture content (Philip and de Vries 1957), and under extremely dry soil conditions the pore vapour pressure is considerably reduced (Jacobs et al. 2000). Thus highlighting soil properties as likely factors influencing dew and water vapour condensation, as well as the morphological feature of the ground surface (Kidron et al. 2002). Chemical analyses of the samples pointed to the high salinity of the BSC surface. Salinity increases the vapour pressure deficit in soil pores, thereby enhancing condensed water vapour (Veste et al. 2008). It appears this reduction is essential for the dew and water vapour condensation process in arid environments. Under dry soil conditions, the relative humidity decreases sharply in the soil pores, which cause a high vapour pressure difference at the soil-atmosphere interface. Water vapour then becomes bound in the soil capillaries and is adsorbed to the soil (Agam and Berliner 2004, 2006).

The increase of clay and silt in the BSC results in higher values of dew and water vapour condensation compared with dune sand, which results in favourable circumstances for the occurrence of microorganisms in the upper soil and hence results in the gradual development of BSC on the soil surface. Due to the fact that microorganisms on the BSC benefit from dew and water vapour condensation, the value of the dew and water vapour condensation increases dramatically for the mossdominated BSC. Therefore, it can be concluded that the dew and water vapour condensation increases with the presence of BSC.

Our results corroborate the research work in the Nizzana sand dune region at northwest Negev Desert, Israel by Heusinkveld et al. (2006), and extend the findings of Kidron et al. (2002) to relate dew and water vapour condensation to the uppermost soil structure, that Kidron et al. (2002) ascribed the higher dew and water vapour condensation on moss-dominated BSC to the structure of the mosses that protrude above the surface.

\section{Implication}

The dew and water vapour condensation simulation experiment was conducted for two typical soil surfaces, moss-dominated BSC and bare dune sand, within the revegetation-stabilized desert ecosystems, NW China, to mimic conditions of the arid desert ecosystem. For its measurement, whole soil columns are placed on a balance with their 
Table 3. Description of physicochemical characteristics of the biological soil crust (BSC) and dune sand (DS) ( $n=6$, mean \pm standard error $)^{a}$.

\begin{tabular}{|c|c|c|c|c|c|c|c|c|}
\hline & \multicolumn{3}{|c|}{ Texture } & \multirow{2}{*}{$\begin{array}{c}\text { Bulk } \\
\text { density } \\
\left(\mathrm{g} \mathrm{cm}^{-3}\right)\end{array}$} & \multirow{2}{*}{$\begin{array}{l}\text { Organic } \\
\text { matter } \\
\left(\mathrm{g} \mathrm{kg}^{-1}\right)\end{array}$} & \multirow[b]{2}{*}{ Porosity } & \multirow[b]{2}{*}{$\mathrm{pH}^{*}$} & \multirow{2}{*}{$\begin{array}{c}\text { Electrical } \\
\text { conductivity* } \\
\left(\mathrm{ms} \mathrm{cm}^{-1}\right)\end{array}$} \\
\hline & $\begin{array}{c}\text { Sand } \\
(\%)\end{array}$ & $\begin{array}{l}\text { Silt } \\
(\%)\end{array}$ & $\begin{array}{c}\text { Clay } \\
(\%)\end{array}$ & & & & & \\
\hline BSC & $57.53 \pm 1.67$ & $37.97 \pm 1.92$ & $4.50 \pm 1.16$ & $1.29 \pm 0.10$ & $7.25 \pm 0.06$ & $0.58 \pm 0.03$ & $7.87 \pm 0.12$ & $112.5 \pm 28.77$ \\
\hline DS & $99.71 \pm 0.06$ & $0.11 \pm 0.01$ & $0.18 \pm 0.01$ & $1.57 \pm 0.34$ & $0.85 \pm 0.01$ & $0.39 \pm 0.01$ & $7.74 \pm 0.13$ & $14.4 \pm 2.12$ \\
\hline
\end{tabular}

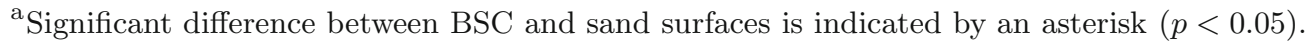

surface at the same height and in the same surroundings as would occur naturally, thus providing a small lysimeter.

Dew and water vapour condensation as an additional source of fresh water, may have a positive impact upon the ecosystems in revegetationstabilized arid desert ecosystems, it serves as the essential moisture source for cryptogams (Kidron et al. 2002) and the BSC (Jacobs et al. 1999). Dew and water vapour condensation is likely important for BSC formation on revegetationstabilized desert ecosystems. This study has important implications for characterizing the relationships between the meteorological conditions and dew and water vapour condensation in terms of soil surface features after stabilizing the moving sand dunes by revegetation techniques. The dew and water vapour condensation accelerates revegetation succession through its benefits in the improvement of local meteorological conditions associated with the development of BSC. The results favour the dew and water vapour condensation and lasting duration on moss-dominated BSC at actual meteorological conditions, which contribute to improve the available surface soil moisture for the ecological effects on cryptogams, microorganisms, indigenous plants, and ephemeral plants. Certainly, in this sense dew and water vapour condensation have considerable ecological significance. The higher amount of dew and water vapour condensation at the BSC is an important driving factor for the improvement of local habitat environment, which further accelerate the formation of BSC and stabilization of moving sand dunes. The presence of BSC, in turn, helps to facilitate the formation of dew and water vapour condensation. Therefore, a mutually, enhanced effect exists between dew and water vapour condensation and the revegetation of arid desert ecosystems.

The amount and duration of the dew and water vapour condensation may be overestimated in the present study because the experiment was conducted in the growth chambers where the influence of wind was eliminated. However, wind was the most important influencing factor for dew and water vapour condensing and persisting. In one of the field experiments at Shapotou, China indicating that around $6 \%$ of less dew was recorded during windy mornings compared to that on a clear and no windy day, though there was no significant relationship found between dew amounts and wind speed (Pan et al. 2010). From the application's point of view, the actual amount of dew and water vapour condensation would be decreased by $6 \%$ of the estimated values under the simulated conditions with no wind effect.

\section{Conclusion}

The amount of dew and water vapour condensation depends upon the dew point, air temperature, and type of condensing surface. It was found that BSC received surprisingly large amount of dew and condensed water vapour compared to bare dune sand. From the foregoing results and discussion, we may conclude that the relative humidity and air temperature play an important role in the dew and water vapour condensation under relatively calm air conditions (e.g., the influence of wind was eliminated). The soil physical and chemical characteristics also induce differences in formation, amount, and duration of dew and water vapour condensation. The findings that more dew and water vapour was condensed on moss-dominated BSC may be related to the greater porosity, finer soil particles, organic matter and higher soil salinity. This is an incidental consequence of surface stabilization by the established straw checker-boards and revegetation activities as compared to the bare dune sand.

\section{Acknowledgements}

This research was funded by one of National Basic Research Programs of China (2013CB429903), the 100-talents Program of the Chinese Academy of Sciences and the National Natural Science Foundation of China (41201085). The authors would like to thank Dr Giacomo Mele for his assistance in measuring pore size distribution. They extend special thanks to the anonymous reviewers for their valuable comments and constructive criticisms that helped to improve the paper. 


\section{References}

Aitken J 1885 On dew; Trans. Roy. Soc. Edin. 33 9-64.

Agam N and Berliner P R 2004 Diurnal water content changes in the bare soil of a coastal desert; J. Hydrometeorol. 5 922-933.

Agam N and Berliner P R 2006 Dew formation and water vapour adsorption in semi-arid environments - A review; J. Arid Environ. 65 572-590.

Angus D E 1958 Measurements of dew; Arid Zone Res. 2 301-303.

Beysens D 1995 The formation of dew; Atmos. Res. 39 215-237.

Clus O, Ouazzani J, Muselli M, Nikolayev V S, Sharan G and Beysens D 2009 Comparison of various radiationcooled dew condensers using computational fluid dynamics; Desalination 249 707-712.

Duvdevani S 1964 Dew in Israel and its effect on plants; Soil Sci. 2 14-21.

Garratt J R and Segal M 1988 On the contribution of atmospheric moisture to dew formation; Bound.-Layer Meteorol. 45 209-236.

Heusinkveld B G, Berkowicz S M, Jacobs A F G, Holtslag A A M and Hillen W C A M 2006 An automated microlysimeter to study dew formation and evaporation in arid and semiarid regions; J. Hydrometeorol. 7 825832.

Jacobs A F G, Heusinkveld B G and Berkowicz S M 1999 Dew deposition and drying in a desert system: A simple simulation model; J. Arid Environ. 42 211-222.

Jacobs A F G, Heusinkveld B G and Berkowicz S M 2000 Dew measurements along a longitudinal sand dune transect, Negev Desert, Israel; Int. J. Biometeorol. 43 184-190.

Jensen M E, Burman R D and Allen R G 1990 Evapotranspiration and irrigation water requirements; ASCE Manuals and Reports on Engin. Practice No. 70, Am. Soc. Civil Eng., New York.

Kidron G J 2000 Analysis of dew precipitation in three habitats within a small arid drainage basin, Negev Highlands, Israel; Atmos. Res. 55 257-270.

Kidron G J, Herrnstadt I and Barzilay E 2002 The role of dew as a moisture source for sand microbiotic crusts in the Negev Desert, Israel; J. Arid Environ. 52 517-533.

Kidron G J 2010 The effect of substrate properties, size, position, sheltering and shading on dew: An experimental approach in the Negev Desert; Atmos. Res. 98 378-386.

Kidron G J, Temina M and Starinsky A 2011 An investigation of the role of water (rain and dew) in controlling the growth form of lichens on cobbles in the Negev Desert; Geomicrobiol. J. 28 1-12.

Li X R, Wang X P, Li T and Zhang J G 2002 Microbiotic soil crust and its effect on vegetation and habitat on artificially stabilized desert dunes in Tengger desert, North China; Biol. Fert. Soils 35 147-154.
Li X Y 2002 Effect of gravel and sand mulches on dew deposition in the semiarid region of China; J. Hydrol. 260 151-160.

McDonald E V 1994 The relative influences of climatic change, desert dust, and lithologic control on soilgeomorphic processes and hydrology of calcic soils formed on Quaternary alluvial-fan deposits in the Mojave Desert, California; Dissertation. University of New Mexico, Albuquerque, New Mexico, USA.

Monteith J L 1957 Dew; Quart. J. Roy. Meteorol. Soc. 83 $322-341$.

Ninari N and Berliner P R 2002 The role of dew in the water and heat balance of bare loess soil in the Negev Desert: Quantifying the actual dew deposition on the soil surface; Atmos. Res. 64 323-334.

Pan Y X, Wang X P and Zhang Y F 2010 Dew formation characteristics in a revegetation-stabilized desert ecosystem in Shapotou area, Northern China; J. Hydrol. 387 $265-272$.

Pedro M J and Gillespie T J Jr 1982 Estimating dew duration. I. Utilizing micrometeorological data; Agr. Meteorol. $25283-296$.

Philip J R and de Vries D A 1957 Moisture movement in porous materials under temperature gradients; Trans. Am. Geophys. Union 38 222-232.

Singer M F 1986 Bulk density-paraffin clod method; In: Field and Laboratory Procedures used in a Soil Chronosequence Study (eds) Singer M J and Janitzky P (U.S. Geol. Survey Bull.), pp. 18-19.

Stone E C 1963 The ecological importance of dew; Quart. Rev. Biol. 38 328-341.

Subramanian A R and Kesava-Rao A V R 1983 Dew fall in sand dune areas of India: Int. J. Biometeorol. 27 271-280.

Veste M, Heusinkveld B G, Berkowicz S M, Breckle S-W, Littmann T and Jacobs A F G 2008 Dew formation and activity of biological soil crusts; In: Arid Dune Ecosystems, Ecological Studies 200 (eds) Breckle S-W, Yair A and Veste M (Berlin, Heidelberg: Springer-Verlag).

Wang X P, Berndtsson R, Li X R and Kang E S 2004 Water balance change for a re-vegetated xerophyte shrub area; Hydrol. Sci. J. 49 283-295.

Wang X P, Li X R, Xiao H L, Berndtsson R and Pan Y X 2007 Effects of surface characteristics on infiltration patterns in an arid shrub desert; Hydrol. Process. 21 72-79.

Wells W C 1815 An essay on dew and several appearances connected with it; 2nd edn (London: Taylor and Hessey).

Ye Y H, Zhou K, Song L Y, Jin J H and Peng S L 2007 Dew amounts and its correlations with meteorological factors in urban landscapes of Guangzhou, China; Atmos. Res. 86 21-29.

Zangvil A and Druian P 1980 Measurements of dew at a desert site in southern Israel; Geograph. Res. Forum 2 26-34.

Zheng R A 1963 The dew characteristics in sandy land; Acta Pedol. Sinica 11 84-91. 